\title{
Teknik Adaptive Pada Modulasi Delta
}

\section{Djadjat Sudaradjat}

Universitas Bina Sarana Informatika

e-mail: djadjat.dsj@bsi.ac.id

Cara Sitasi: Sudaradjat, D. (2019). Teknik Adaptive pada Modulasi Delta. Paradigma - Jurnal Komputer dan Informatika, 21(1), 137-142. doi:10.31294/p.v21i2.5632

\begin{abstract}
DM(Delta Modulation) is one of the waveform coding methods that converts analog waveforms into digital waveforms, by encoding binary numbers 1 when analog waveforms rise, and encodes binary numbers 0 when analog waveforms drop, and if analog waveforms are flat will be encoded binary numbers 1 and 0 alternately. So that the row of binary numbers 1 and 0 will show the fluctuation of the analog signal form. Problems faced in Delta Modulation when the ups and downs of analog waveforms are too steep or too tilted so that analog waveform changes cannot be followed, there will be slope overload noise, which causes SNR (Signal to Noise Ratio) to shrink because it is unable follow the analog wave changes which are too high to produce a large noise. For this reason, Adaptive techniques are made, so that excess can be avoided, thereby reducing the Noise and SNR expected to be obtained. ADM (Adaptive Delta Modulation) reduces load tilt errors, and seeks to increase dynamic range. Adaptive algorithms adjust the step size (from various step sizes) to the signal power level and thus increase the dynamic range of the coding system. This paper discusses Delta Modulation techniques for increasing SNR with ADM techniques, as well as performance comparisons between DM and ADM.
\end{abstract}

Keywords: Adaptive Delta Modulation, Analog to Digital Converter (ADC), Speech Compression.

\section{PENDAHULUAN}

Semua teknologi kabel dan nirkabel baru-baru ini sudah beralih ke digital. Oleh karena itu, perangkat penyimpanan digital dan metode pengkodean digital memiliki prioritas ketika mengembangkan sistem komunikasi, terutama dalam komunikasi suara manusia. Sehingga konverter analog-ke-digital dan digital-ke-analog untuk encode dan decode masingmasing harus dirancang dengan kualitas layanan yang diperlukan dan ketersediaan sumber daya. Untuk suara manusia, dengan kecepatan cuplik sebesar 8000 cuplik per detik digunakan pada system PCM (Pulse Code Modulation) dengan 256 tingkat kuantisasi dihasilkan kecepatan bit $64 \mathrm{kbps}$ laju pengiriman data. Ini membutuhkan sumber daya pita frekuensi yang lebar, untuk membuat perangkat portabel dengan biaya rendah dan daya rendah. (Smadi, Taweel, \& Igried, 2017)

Delta modulation (DM) adalah teknik konversi analog-ke-digital sederhana yang banyak digunakan dalam pengkodean dan kompresi sinyal analog, seperti ucapan manusia, audio, gambar, dll. Seperti pada Differential Pulse Code Modulation (DPCM), DM adalah DPCM dengan kompleksitas rendah, di mana pada pengkodeannya hanya menggunakan satubit. Mengingat kompleksitasnya yang rendah dan kinerja yang solid, DM adalah kandidat yang baik untuk implementasi waktu nyata. Baik DPCM dan DM termasuk dalam kelompok algoritma pengkodean prediktif, yang sering digunakan dalam pemrosesan sinyal adaptif, pemrosesan sinyal kognitif, peningkatan kemampuan berbicara dan kecerdasan buatan (Peric, Denic, \& Despotovic, 2019).

(a) Transmitter :

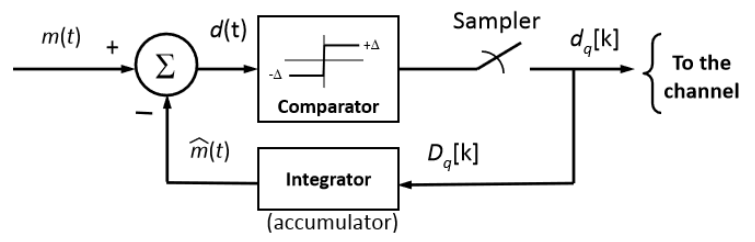

(b) Receiver :

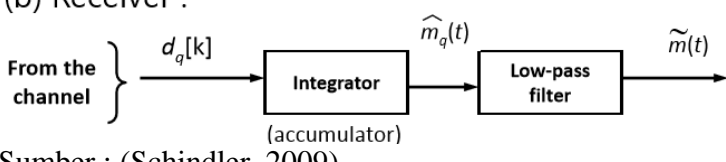

Sumber : (Schindler, 2009)

Gambar 1. (a) Modulator Delta.

(b) Demodulator Delta.

Blok diagram system modulasi Delta yang Linier (Linier Delta Modulation, LDM) diperlihatkan di gambar 1. Bagian modulator, terdiri dari Comparator, Sampler, dan Integrator. Bagian demodulator terdiri 
dari integrator dan LPF (Low Pass Filter). Komparator dapat membandingkan sinyal analog $\mathrm{m}(\mathrm{t})$ dengan sinyal umpan balik $\widehat{m}(\mathrm{t})$, dan menyatakannya kedalam dua level tegangan positip dan negatip. Perbedaan kedua masukan tersebut adalah $d(t)=m(t)-\widehat{m}(t)$. Dengan mengasumsikan persamaan keluaran komparator adalah :

$d_{q}(t)=\Delta \operatorname{sgn}[e(t)]$

Dimana : $\Delta$ adalah harga konstan, maka dari persamaan (1) dapat disimpulkan bahwa komparator akan menghasilkan tegangan sebesar $+\Delta$, jika $e(t)>0$, dan sebesar $-\Delta$, jika $e(t)<0$.

Keluaran komparator tersebut ditransmisikan oleh rangkaian Sampler dalam bentuk pulsa persegi $d_{q}(k)$ dengan besar tegangan $\pm \Delta$, dan dengan kecepatan pulsa yang sama dengan kecepatan Sampler.

Rangkaian integrator berfungsi untuk menghasilkan sinyal umpan-balik $\widehat{m}(\mathrm{t})$, yang diperoleh dengan mengintegrasi pulsa biner $d_{q}(t)$. Respons rangkaian integrator terhadap pulsa persegi akan berbentuk eksponensial (Sudaradjat, 1987). Rangkaian ini menaikkan harga $\widehat{m}(\mathrm{t})$ jika $d_{q}(t)>0$, dan menurunkan harga $\widehat{m}(\mathrm{t})$ jika $d_{q}(t)<0$.

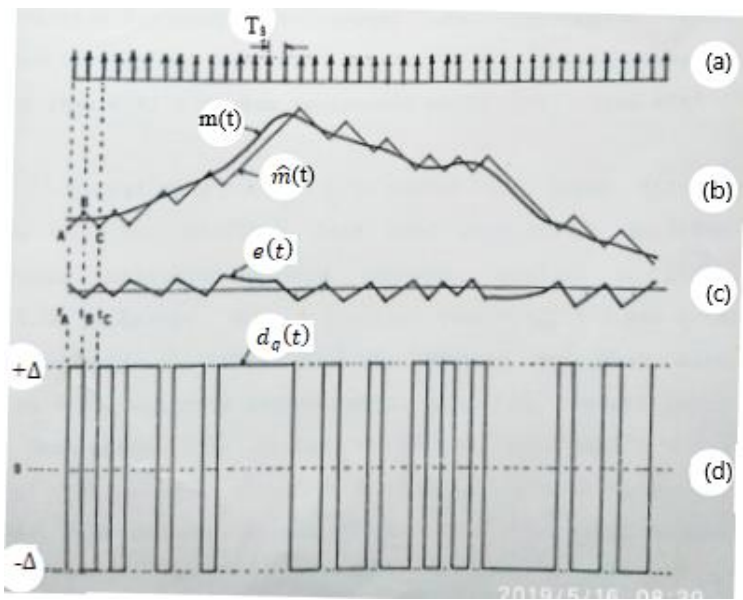

Sumber : (Sudaradjat, 1987)

Gambar 2. (a) Pulsa Sampler. (b) Sinyal analog m(t) dan sinyal umpan balik $\widehat{m}(\mathrm{t})$. (c) Sinyal error e(t). (d) Pulsa biner $d_{q}(t)$.

Sinyal yang terjadi pada system LDM dapat dilihat di gambar 2. Misalkan pada saat pengambilan sampler pertama, integrator memiliki tegangan awal di A, lihat gambar 2(b). Karena $m\left(t_{\mathrm{A}}\right)>\widehat{m}\left(\mathrm{t}_{\mathrm{A}}\right)$, maka $\mathrm{e}\left(\mathrm{t}_{\mathrm{A}}\right)$ $>0$ dan $d_{q}(t)$ akan berharga $+\Delta$, lihat gambar 2(d). Sebagai akibatnya maka harga $\widehat{m}(\mathrm{t})$ akan naik dengan waktu, umpamanya sebagai garis AB. Pada pengambilan cuplikan berikutnya yaitu pada $t=t_{B}$, $\mathrm{m}\left(\mathrm{t}_{\mathrm{B}}\right)<\widehat{m}\left(\mathrm{t}_{\mathrm{B}}\right)$, maka e $\left(\mathrm{t}_{\mathrm{B}}\right)<0$ dan $\mathrm{d}_{\mathrm{q}}(\mathrm{t})$ akan berharga $-\Delta$. Harga $\mathrm{d}_{\mathrm{q}}(\mathrm{t})$ ini akan mengakibatkan harga $\widehat{m}(\mathrm{t})$ turun dengan waktu, umpama seperti garis BC di gambar 2(b). Keadaan serupa terjadi pada langkah berikutnya. Akibatnya $\widehat{m}(\mathrm{t})$ akan selalu berusaha mengikuti $\mathrm{m}(\mathrm{t})$.

Pada Demodulator Delta, $\widehat{m}_{q}(t)$ dapat diperoleh dengan mengintegrasi deretan pulsa $\mathrm{d}_{\mathrm{q}}(\mathrm{t})$. Selanjutnya untuk menghilangkan komponen frekuensi tingginya, sinyal $\widehat{m}_{q}(t)$ keluaran integrator dilewatkan suatu LPF, sehingga akan diperoleh sinyal analog $\tilde{m}(t)$ yang menyerupai bentuk $\mathrm{m}(\mathrm{t})$. (Sudaradjat, 1987)

Apabila sinyal masukan analog $\mathrm{m}(\mathrm{t})$ berubah terlalu cepat, maka $\widehat{m}_{q}(t)$ tak mampu mengikuti $\mathrm{m}(\mathrm{t})$, seperti terlihat di gambar 3. Peristiwa demikian disebut Overload yang akan mengakibatkan gangguan pada penerima dan disebut Slope-overload distortion.

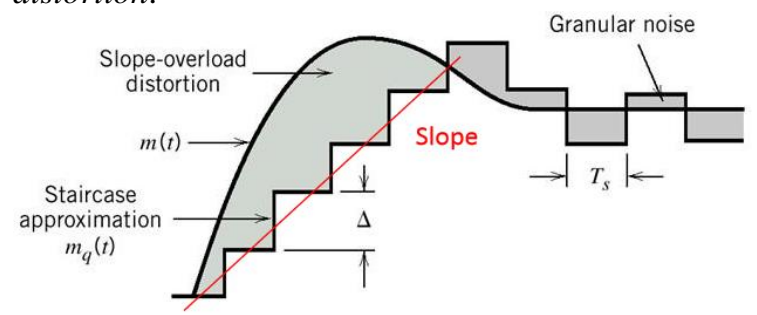

Sumber : (Schindler, 2009)

Gambar 3. Overload.

Persyaratan kerja system LDM agar tidak mengalami overload dapat dijelaskan sebagai berikut : anggap bahwa perioda $\mathrm{T}_{\mathrm{s}}$ dari cuplikan jauh lebih kecil dari perioda komponen sinusoida tertinggi dari sinyal. Di gambar 3 diperlihatkan bahwa selama satu interval cuplik $\mathrm{T}_{\mathrm{s}}, \widehat{m}_{q}(t)$ berubah sebesar $\Delta$, yaitu sebesar langkah satu cuplikan (delta step). Maka kemiringan dari $\widehat{m}_{q}(t)$ adalah $\Delta / \mathrm{T}_{\mathrm{s}}$ atau $\Delta . \mathrm{f}_{\mathrm{s}}$, dimana $\mathrm{f}_{\mathrm{s}}$ adalah frekuensi cuplik (sampling). Anggap $m(t)$ adalah sinyal sinusoida, dengan persamaan :

$m(t)=\mathrm{A} \sin W t$

Maka : $\frac{d m(t)}{d t}=W A \cos W t$

Dengam anggapan tersebut, agar tak terjadi overload, kemiringan $\mathrm{m}(\mathrm{t})$ harus selalu lebih kecil dari pada kemiringan $\widehat{m}_{q}(t)$ dan pada batasnya sama dengan kemiringan $\widehat{m}_{q}(t)$. Maka agar tak terjadi overload harus dipenuhi :

$\left|\frac{d m(t)}{d(t)}\right|_{m a k}=W A \leq \Delta . \mathrm{f}_{\mathrm{s}}$

Karena itu agar tak terjadi overload maka :

$\mathrm{A}_{\text {mak }}=\frac{\Delta \cdot \mathrm{fs}}{W}$

Dari persamaan (5) dapat disimpulkan bahwa agar kondisi tak terjadi overload selalu harus dipenuhi, amplitude komponen sinyal harus turun dengan naiknya frekuensi. 


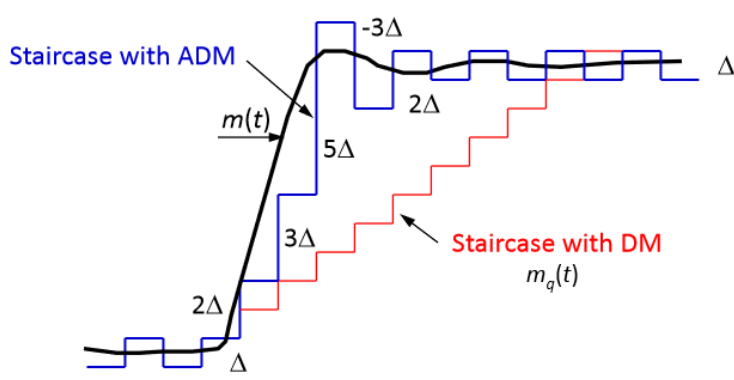

$\begin{array}{lllllllllllllllll}1 & 0 & 1 & 1 & 1 & 1 & 0 & 1 & 0 & 1 & 0 & 1 & 0 & 1 & 0 & \ldots\end{array}$ Sumber : (Schindler, 2009)

Gambar 4. Staircase with ADM.

Pada ADM seperti yang ditunjukkan di gambar 4, tujuannya adalah menerapkan aturan adaptasi pada ukuran langkah agar dapat melacak dengan baik perubahan dalam sinyal input. Oleh karena itu, ADM beroperasi dengan ukuran langkah variabel, berbeda dengan DM standar (juga dikenal sebagai Linear Delta Modulation (LDM)) yang menawarkan ukuran langkah konstan pada setiap cuplikan. Dengan cara itu, ADM cenderung mengatasi masalah kemiringan distorsi berlebih (overload) yang terjadi pada standar DM. DM dapat juga dianggap sebagai kasus khusus DPCM yang hanya menggunakan pengkodean 1 bit. (Peric, Denic, \& Despotovic, 2018)

ADM kemudian dipilih sebagai standar untuk semua komunikasi NASA antara mission control dan spacecraft (Smadi et al., 2017), ADM adalah modifikasi DM di mana ukuran langkah tidak tetap. Sebaliknya, ketika beberapa bit berturut-turut memiliki nilai arah yang sama, encoder dan decoder mengasumsikan bahwa kemiringan yang berlebihan terjadi, dan ukuran langkah menjadi semakin besar, sehingga peran ADM diperlukan untuk mengatasinya.

\section{METODOLOGI PENELITIAN}

Prinsip kerja system ADM pada penelitian disini seperti diperlihatkan pada blok diagram di gambar 5 . Deretan pulsa $\mathrm{d}(\mathrm{t})$ keluaran modulator akan memberikan informasi tentang slope sinyal $\mathrm{m}(\mathrm{t})$. Jika slope sinyal $\mathrm{m}(\mathrm{t})$ berada di bawah batas overload, maka modulator akan menghasilkan deretan pulsa yang berganti-ganti secara acak berupa deretan pulsa 'satu' dan 'nol', dan jika slope sinyal m(t) berada di daerah batas overload (maksimum), maka modulator akan menghasilkan deretan pulsa yang berpolarisasi sama.

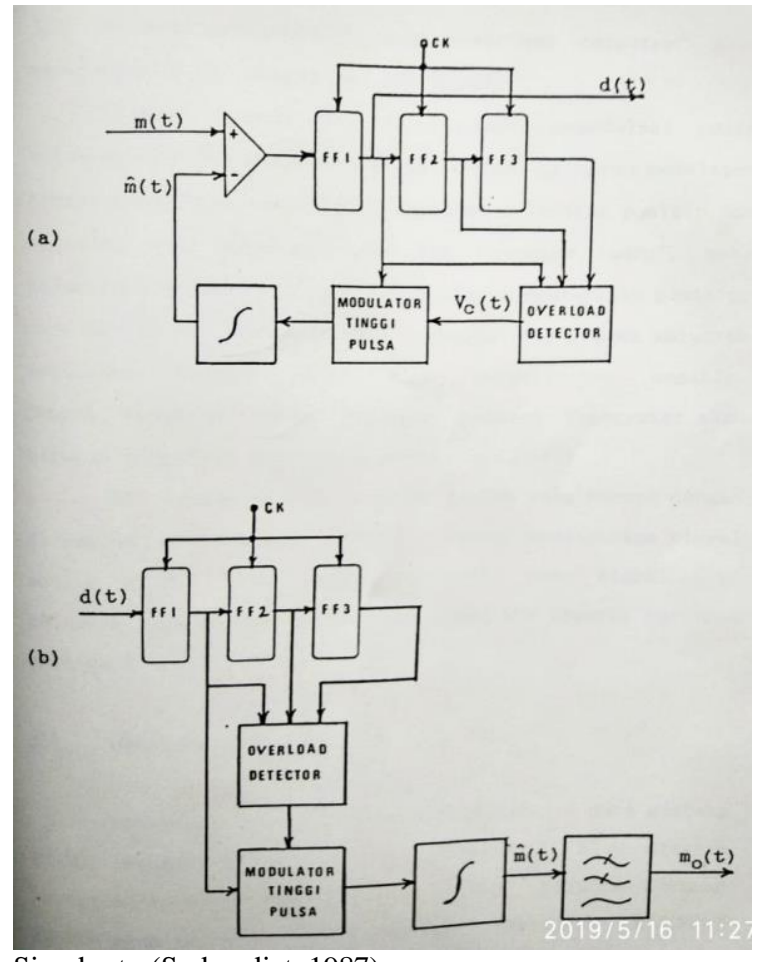

Siumbert : (Sudaradjat, 1987)

Gambar 5. (a) Modulator ADM. (b) Demodulator ADM.

Karena itu kondisi overload dapat dideteksi oleh 'overload detector' yang mengambil masukan dari keluaran FF1, FF2, dan FF3. Deretan ketiga flip-flop tersebut merupakan suatu shift register tiga tahap. Jika keluaran FF1, FF2, dan FF3 sama polaritasnya, maka 'overload detector' akan menaikkan harga sinyal control $\mathrm{V}_{\mathrm{c}}(\mathrm{t})$, dan jika berbeda polaritasnya, maka 'overload detector' akan menurunkan harga sinyal control $\mathrm{V}_{\mathrm{c}}(\mathrm{t})$.

Sinyal control $\mathrm{V}_{\mathrm{c}}(\mathrm{t})$ tersebut memodulasi pulsa keluaran FF1 di modulator tinggi pulsa. Keluaran modulator tinggi pulsa tersebut dibuat memiliki polaritas positip dan negatip. Jika pulsa keluaran FF1 berharga 'satu', maka keluaran modulator tinggi pulsa akan berpolaritas positip, dan jika pulsa keluaran FF1 berharga 'nol', maka keluaran modulator tinggi pulsa akan berpolaritas negatip. Dengan demikian besar tegangan masukan integrator akan berubah mengikuti perubahan slope sinyal $\mathrm{m}(\mathrm{t})$.

Di bagian demodulator terjadi proses yang serupa dengan dibagian umpan-balik modulator, untuk mendapatkan sinyal analog $\mathrm{m}_{\mathrm{o}}(\mathrm{t})$ yang menyerupai $\mathrm{m}(\mathrm{t})$, maka sinyal $\hat{m}(\mathrm{t})$ keluaran integrator dilewatkan suatu LPF seperti terlihat di gambar 5(b).

'Overload detector' yang dibuat terdiri dari gerbang EX-NOR dengan 3 masukan, dan integrator, seperti yang diperlihatkan di gambar 6. Keluaran gerbang EX-NOR akan berharga 'satu' jika pulsa keluaran FF1, FF2, dan FF3 berpolaritas sama, dan berharga 'nol' jika berbeda polaritas. Tabel kebenaran gerbang 
EX-NOR tersebut dapat dilihat di tabel 1. Integrator akan mengintegrasi keluaran gerbang EX-NOR untuk mendapatkan sinyal keluaran yang bergerak naik jika keluaran gerbang EX-NOR berharga 'satu, dan turun jika keluaran gerbang EX-NOR berharga 'nol'. Untuk lebih jelasnya, contoh sinyal yang terjadi pada gerbang EX-NOR dan integrator diperlihatkan di gambar 7 .

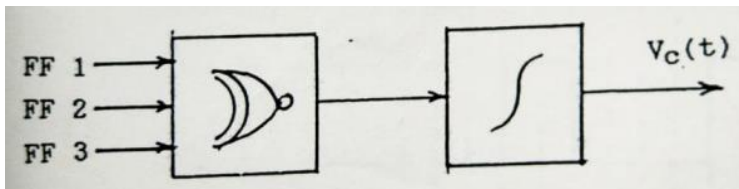

Sumber : (Sudaradjat, 1987)

Gambar 6. 'Overload Detector'.

Tabel 1. Tabel kebenaran dari gerbang EX-NOR dengan 3

\begin{tabular}{ccccc} 
FF1 & FF2 & FF3 & EX-OR & $\begin{array}{c}\text { EX- } \\
\text { NOR }\end{array}$ \\
\hline $\mathbf{1}$ & 1 & 1 & 0 & 1 \\
\hline $\mathbf{1}$ & 1 & 0 & 1 & 0 \\
\hline $\mathbf{1}$ & 0 & 1 & 1 & 0 \\
\hline $\mathbf{1}$ & 0 & 0 & 1 & 0 \\
\hline $\mathbf{0}$ & 1 & 1 & 1 & 0 \\
\hline $\mathbf{0}$ & 1 & 0 & 1 & 0 \\
\hline $\mathbf{0}$ & 0 & 1 & 1 & 0 \\
\hline $\mathbf{0}$ & 0 & 0 & 0 & 1 \\
\hline
\end{tabular}

Sumber : (Sudaradjat, 1987)

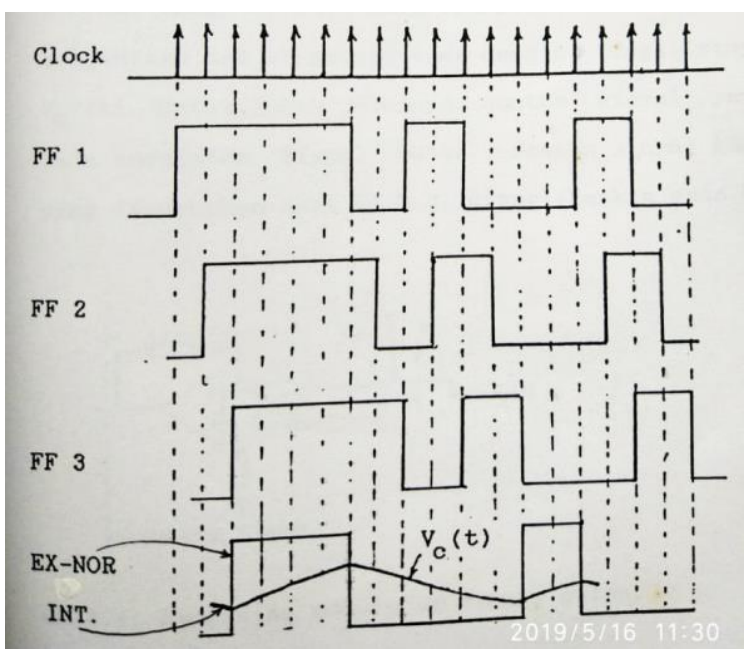

Sumber : (Sudaradjat, 1987)

Gambar 7. Sinyal yang terjadi pada EX-NOR dan Integrator.

Rangkaian modulator tinggi pulsa yang dibuat diperlihatkan pada gambar 8. Pulsa keluaran Q dan $\bar{Q}$ dari FF1 digunakan untuk mengendalikan saklar, yaitu saklar I yang tertutup jika $\bar{Q}=1$, dan terbuka jika $\bar{Q}=$ 0 , saklar II yang tertutup jika $Q=1$, dan terbuka jika $\mathrm{Q}=0$. Penguatan dari pengubah level tegangan dibuat berharga -1 untuk keluaran saklar I, dan +1 untuk keluaran saklar II. Sebagai akibatnya, keluaran pengubah level tegangan akan berupa sinyal yang berpolarisasi positip dan negatip secara bergantian dan tingginya sama dengan tinggi sinyal kontrol $V_{c}(t)$. untuk lebih jelasnya, contoh sinyal yang terjadi pada modulator tinggi pulsa, dengan sinyal kontrol $\mathrm{V}_{\mathrm{c}}(\mathrm{t})$ yang diturunkan dari gambar 7, diperlihatkan pada gambar 9.

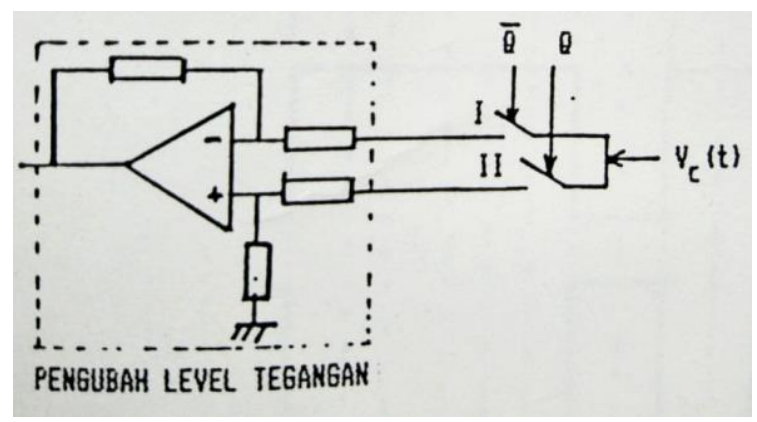

Sumber : (Sudaradjat, 1987)

Gambar 8. Rangkaian modulator tinggi pulsa.

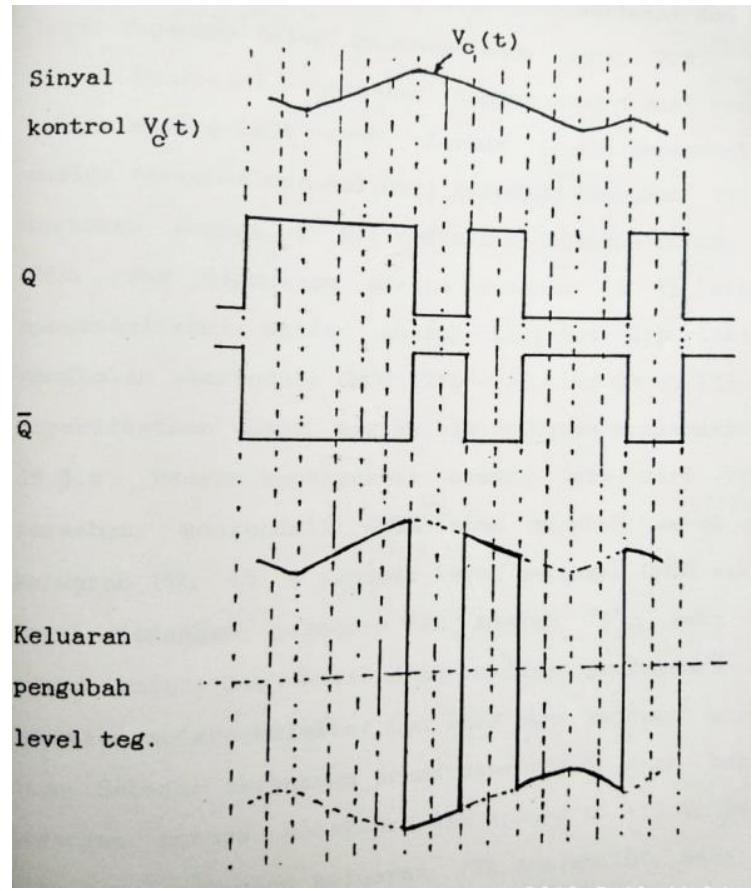

Sumber : (Sudaradjat, 1987)

Gambar 9. Sinyal yang terjadi pada modulator tinggi pulsa. (a) Sinyal control $V_{c}(t)$. (b) Pulsa keluaran FF1. (c) Keluaran pengubah level tegangan.

Rangkaian lengkap modulator ADM yang dibuat terlihat pada gambar 10 . 


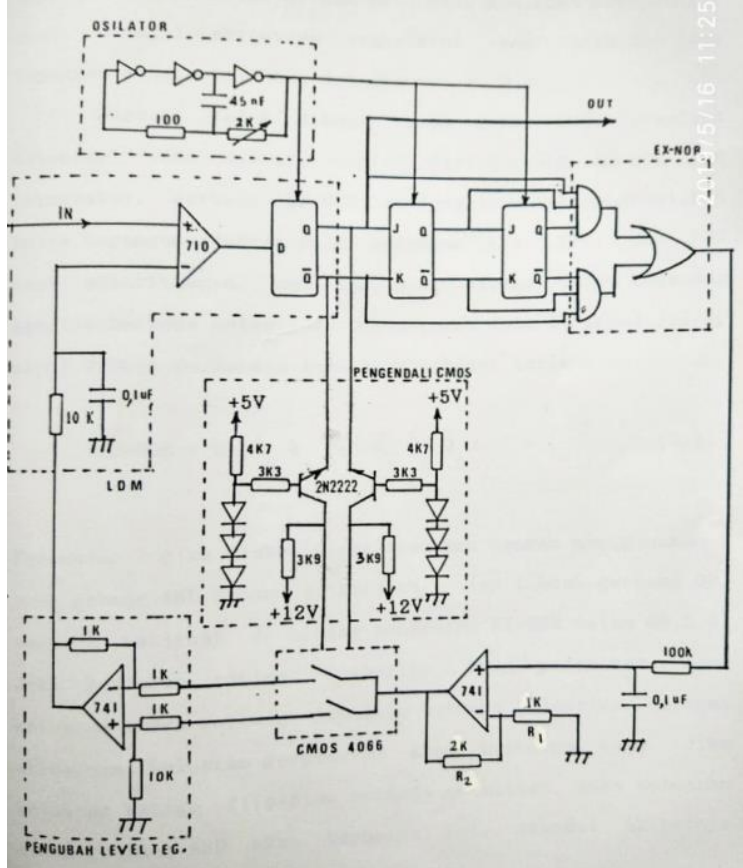

Sumber : (Sudaradjat, 1987)

Gambar 10. Rangkaian lengkap encoder ADM.

\section{HASIL DAN PEMBAHASAN}

Hasil pengukuran di pasal ini akan dilakukan pengukuran terhadap $\mathrm{S} / \mathrm{N}$ sebagai fungsi amplituda sinyal pada frekuensi $800 \mathrm{~Hz}$.

Diagram blok pengukuran derau yang dipakai adalah seperti terlihat pada gambar 11 .

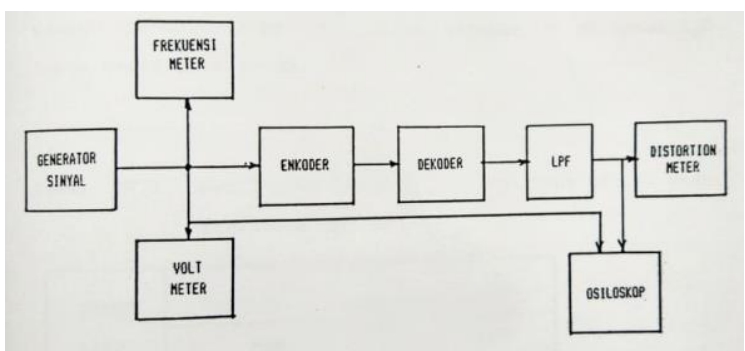

Sumber : (Sudaradjat, 1987)

Gambar 11. Blok diagram pengukuran derau.

Pengukuran ini dilakukan untuk mengetahui 'dynamicrange' system ADM dan LDM pada frekuensi cuplik $16 \mathrm{KHz}$ dan bandwidth filter 2,4 KHz. 'Dynamicrange' didefinisikan sebagai perbandingan amplitude terbesar dengan amplitude terkecil yang berada diantara S/N maksimum sampai $3 \mathrm{~dB}$ dibawah $\mathrm{S} / \mathrm{N}$ maksimum (Sudaradjat, 1987). Hasil pengukuran dicatat pada tabel 2, dan digambarkan dengan kurva pada gambar 12. Dari tabel dan gambar kurva tersebut tampak bahwa system ADM dapat menghasilkan S/N maksimum sebesar $20 \mathrm{~dB}$ dengan 'dynamic-range' kira-kira sebesar $20 \mathrm{~dB}$ untuk S/N lebih besar dari 17 $\mathrm{dB}$, sedangkan system LDM dapat menghasilkan S/N maksimum sebesar $20 \mathrm{~dB}$ dengan 'dynamic-range' kira-kira selebar $9 \mathrm{~dB}$ untuk S/N lebih besar dari $17 \mathrm{~dB}$.

Tabel 2. Hasil pengukuran $\mathrm{S} / \mathrm{N}$ vs amplitude sinyal pada

\begin{tabular}{ccc} 
& frekuensi $800 \mathrm{~Hz}$. \\
\hline & \multicolumn{2}{c}{$\mathbf{S} / \mathbf{N}(\mathbf{d B})$} \\
\cline { 2 - 3 } INPUT $(\mathbf{d B V})$ & ADM & LDM \\
\hline & 16 & - \\
\hline $\mathbf{+ 6}$ & 17 & - \\
\hline $\mathbf{+ 4}$ & 17,5 & 14,4 \\
\hline $\mathbf{+ 2}$ & 18,5 & 16,5 \\
\hline $\mathbf{0}$ & 19,5 & 18,2 \\
\hline $\mathbf{- 2}$ & 20 & 19,5 \\
\hline $\mathbf{- 4}$ & 20 & 20 \\
\hline $\mathbf{- 6}$ & 20 & 18 \\
\hline $\mathbf{- 8}$ & 19,5 & 16,2 \\
\hline $\mathbf{- 1 0}$ & 19,5 & 13,4 \\
\hline $\mathbf{- 1 2}$ & 17,4 & 13,2 \\
\hline $\mathbf{- 1 4}$ & 17 & 9,2 \\
\hline $\mathbf{- 1 6}$ & 15 & - \\
\hline $\mathbf{- 1 8}$ & 13,2 & - \\
\hline $\mathbf{- 2 0}$ & &
\end{tabular}

Sumber : (Sudaradjat, 1987)

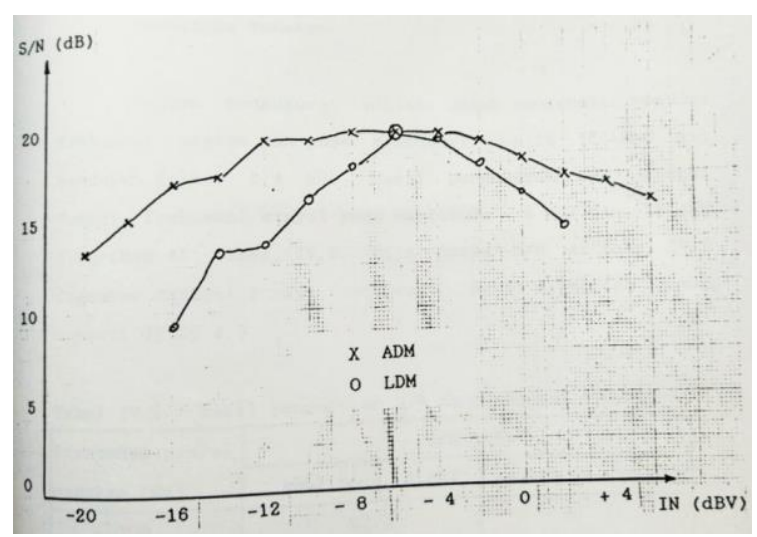

Sumber : (Sudaradjat, 1987)

Gambar 12. Kurva S/N vs amplitude sinyal pada frekuensi $800 \mathrm{~Hz}$.

Dari hasil pengukuran tersebut tampak bahwa system ADM dapat menghasilkan 'dynamic-range' yang lebih lebar dari pada system LDM. Tetapi kedua system tersebut menghasilkan $\mathrm{S} / \mathrm{N}$ maksimum yang sama besar, yaitu sebesar $20 \mathrm{~dB}$. Secara keseluruhan dapat disimpulkan bahwa system ADM yang dibuat sesuai dengan yang direncanakan (Sudaradjat, 1987).

\section{KESIMPULAN}

Sistem ADM yang dibuat pada penelitian disini merupakan sistem konversi analog ke dijital yang cukup sederhana, dan memungkinkan untuk menghasilkan bit-rate yang rendah. Pada pengukuran sinyal sinusoida dengan frekuensi $800 \mathrm{~Hz}$ dan bit-rate $16 \mathrm{kbps}$, sistem ADM yang dibuat menghasilkan S/N maksimum sebesar $20 \mathrm{~dB}$, dan 'dynamic-range' selebar $20 \mathrm{~dB}$ untuk S/N lebih besar dari $17 \mathrm{~dB}$.

'Dynamic-range' yang dihasilkan sistem ADM lebih 
lebar dari pada yang dihasilkan sistem LDM, dengan $\mathrm{S} / \mathrm{N}$ maksimum yang sama besar untuk kedua sistem tersebut. Ini menunjukkan bahwa sistem ADM yang dibuat dapat menghasilkan sinyal adaptive yang variabel, sehingga mengurangi 'slope overload Noise'.

Pengembangan sistem ADM dapat dilakukan dengan berbagai cara agar sinyal adaptive yang dihasilkan dapat mengikuti perubahan sinyal masukan yang berubah cepat, dan menghasilkan $\mathrm{S} / \mathrm{N}$ yang tinggi dan 'dynamic-range' yang lebar. Sehingga sinyal rekonstruksi di penerima akan menghasilkan sinyal dengan kualitas semirip mungkin dengan sinyal aslinya.

\section{REFERENSI}

Peric, Z., Denic, B., \& Despotovic, V. (2018). Threelevel delta modulation with second- order prediction for Gaussian source coding. Advances in Electrical and Computer Engineering, 18(3), 125-130. https://doi.org/10.4316/AECE.2018.03017

Peric, Z., Denic, B., \& Despotovic, V. (2019). Novel
Two-Bit Adaptive Delta Modulation Algorithms. 30(1), 117-134.

Schindler, H. R. (2009). Delta modulation. IEEE Spectrum, 7(10), 69-78. https://doi.org/10.1109/mspec.1970.5212996

Smadi, T. Al, Taweel, F. M. Al, \& Igried, A. (2017). Estimation and Design Techniques for Adaptive Delta Modulation Using Otas. 1(2), 49-52.

https://doi.org/10.11648/j.ajset.20160102.15

Sudaradjat, D. (ITB). (1987). LOW BIT-RATE DELTA MODULATION. Institut Teknologi Bandung.

\section{PROFIL PENULIS}

Ir. Djadjat Sudaradjat, MT. Lulus S-1 tahun 1987, Jurusan Teknik Elektro, Fakultas Teknologi Industri, Institut Teknologi Bandung. Lulus S-2 tahun 1993, Sub Program Studi Sistim Informasi Listrik, Program Magister Elektroteknik, Program Pasca Sarjana, Institut Teknologi Bandung. Sekarang menjadi Dosen di Universitas Bina Sarana Informatika, NIDN : 0302036201. 